\title{
Managing Reciprocity: No Harm Approaches to International Educational Placements
}

The idea of 'win-win' outcomes from international mobility is not new. Critiques of the 'brain drain' concept presented new hopes of mutually beneficial knowledge mobilisation referring to the returns to 'sending' countries via circulatory processes and virtual mobilities (Meyer 2003; Regets 2003). Our own work on scientific mobility concluded that brain drain as a concept was far too narrow and failed to capture the relationship between human mobility and knowledge mobilisation processes and the fact that mobility is the lifeblood of science in many resource starved regions (Ackers and Gill 2007). But these relationships are highly complex and there is no effective way of (quantitatively) 'measuring' losses and gains. To speak of win-win is to fail to capture these complexities and the critical importance of context to any evaluation of impact (Bate 2014). Our action-research study of ethical educational placements concludes that such exposures create transformational learning opportunities for the UK students involved. And these opportunities have the potential to make a significant contribution to the learning outcomes of direct relevance to curricula in their home universities. From the perspective of student learning we have no doubts that spending a period in a low resource setting is uniquely valuable. The learning premium and its specific relationship with core learning outcomes associated with academic study programmes will vary quite significantly depending on the structure and organisation of placements.

Placements organised through private sector companies capitalising on the swelling demand for volunteer-tourism, fuelled by university

(C) The Author(s) 2017 
internationalisation processes, will generate some forms of useful learning. Taking students outside of their own country and the health systems they are accustomed to will necessarily develop systems thinking. It will push students out of their comfort zones and create opportunities for exposure to and reflection on cultural difference and global inequalities with the potential to build competence in global citizenship. Having said, that we have serious concerns that, unless placements are framed appropriately and adequate systems are in place to manage this process of intense engagement in a foreign environment there is a high risk that the 'shock' effects of what some authors have termed 'poverty tourism' (Dowell and Merrylees 2009 $)^{1}$ could reinforce stereotypes. Simply being immersed in a low resource setting for four weeks and observing poverty does not necessarily translate into cultural competence. It may have quite the opposite effect. An important concern for placement providers here is to ensure a level of cultural awareness and understanding that goes beyond the potentially damaging effects of what Simpson calls the 'essentialized concepts of 'other' (2004: 682).

To the extent that international educational placements are just that: namely 'electives' (implying optional choices out with the core curricu$\operatorname{lum})^{2}$ participation in forms of gap-year voluntourism provided by private companies may deliver valuable learning opportunities. And universities will (hopefully) pick up and challenge incidences of cultural 'mislearning' in reflective components of emerging global health curricula. We have serious doubts that such encounters generate the kind of curriculum-relevant learning that we have evidenced in the EEP project. Achieving this requires a much higher level of engagement that goes beyond quite voyeuristic 'observation-only' placements captured by Wearing and McGehee as a form of 'shallow volunteering' (2013: 123) and guards against the arrogance and risks associated with 'free mover'

${ }^{1}$ A shocking example of this has been described as 'orphanage tourism.' We have direct experience of the ways in which orphanages have been developed in Uganda as commodified 'honey pots' to attract gap-year students and the income associated with this 'market' creating new partnerships in corruption and opportunities for child abuse. For details, see http://www.thinkchildsafe.org/thinkbeforevisiting/ ${ }^{2}$ Wikipedia defines 'An elective course is one chosen by a student from a number of optional subjects or courses in a curriculum, as opposed to a required course which the student must take' https://en.wikipedia.org/wiki/Course_(education) 
medical electives. Achieving optimal curriculum and practice-relevant learning requires direct engagement with university programmes and effective supervision. When these structures are in place and embedded in active partnership working, international placements in low resource settings have the potential to become part of the core curriculum. This process of moving from 'out-of-program' electives to 'within-program' educational placements is important for a number of reasons. Firstly, because the learning returns in carefully planned and funded placements justify full recognition within education programmes. Secondly, because electives are inherently and increasingly associated with profound inequalities of opportunity. Notre Dame University defines electives as 'optional' but that does not imply free choice; the ability to access them has in the main reflected students' financial status (or that of their parents). As Wearing and McGehee note, most participants in international elective schemes have come from middle-class backgrounds (2013: 121).

Raymond and Hall go further suggesting that volunteer tourism exists in a highly commodified environment and serves as a 'stronghold for the privileged' (Raymond and Hall 2008). Social class and attitudes towards mobility are not a simple reflection of financial resource; they also reflect cultural or mobility 'capital'. Students who have been exposed to foreign travel at a younger age or for whom it has been a cultural expectation or rite of passage (as the medical elective often is) are far more likely to seek out elective placements and to process and manage the perceived risks involved. Most of the students who have taken part in the funded components of the EEPs are not in that situation and the EEP represents the first opportunity they have ever had to travel to a low resource setting. Certainly, most would not have taken this step without the encouragement and support of the project.

The funding provided by Health Education England coupled with the institutional support offered through the University of SalfordKnowledge for Change partnership facilitated these mobilities. The growing 'expectation of mobility' and the tendency for this to influence student opportunities and life chances at ever earlier stages in their education places pressure on education providers to recognise and respond to the inherent inequalities this presents. One of the major providers of placements, 'Work the World' advertises its dentistry placements with the strapline: 'A specialist dentistry placement with us will set you apart from anyone who chose to play it safe and 
stay in the UK' ${ }^{3}$ The website advertises placements at a basic cost of $£ 1390$ for four weeks (plus $£ 300$ registration fee) excluding international flights making a placement cost in the region of $£ 2300$. Another provider (Projects Abroad) ${ }^{4}$ provide a price list depending on the location and type of placements to around $£ 1,800$ (for four weeks) taking the price including flights and visas to over $£ 2500$. These are far cheaper than many other providers with students reporting costs of over $£ 4000$ for elective placements often with an additional expectation of donations attached. As Hartman et al. describe, higher education and volunteering represent the largest growth sectors in the youth and tourism industry in a market which they estimate to be worth over 2 billion dollars globally. Wearing and McGehee in their review of the burgeoning literature on 'volunteer tourism' cite figures suggesting that volunteer tourists spend between $£ 838 \mathrm{~m}$ and $£ 1.3 \mathrm{~b}$ per year (2013: 120$)$.

An international placement is not an 'elective' if a student cannot afford to access it or lacks the confidence to engage. Bringing placements inprogramme renders the inequalities explicit and forces key actors in universities and the NHS to recognise and respond to them. The process will also put pressure on private providers engaged in the commodification of placements to show value-for-money. It will also expose the genuine costs of this form of activity to universities enabling them to consider their role in the new fees structure for nursing, midwifery and allied health professions and the possibility of developing equitable ways of managing these to an increasingly diverse student body.

So far, we have discussed the benefits of international placements to the students in 'sending' countries and the potential costs involved raising issues of equity and quality. When ethics are raised in the context of placements the discussion is usually with the impacts on 'host' settings. Most of the private providers offering placements pay at least lip service to the development impacts of placements typically referring to either cash payments or donations as forms of compensatory 'payments' in this commodified environment. By way of example 'Work the World" advertise

\footnotetext{
${ }^{3}$ http://www.worktheworld.co.uk/dentistry-electives

${ }^{4}$ http://projects-abroad.co.uk/

${ }^{5}$ See note 3 .
} 
the 'support for partners' offered through their schemes stating that, 'we make a point of recognising [our supervising staff] by financially rewarding them, personally, for their efforts'. Furthermore, 'a fixed sum is given to each and every hospital for every student we send'. They go on to show photographs of huge volumes of consumables donated to facilities and to list equipment donations. Whilst it is important not to underplay the potential value of these forms of compensation each component of this raises serious concerns to anyone with a knowledge and understanding of working in low resource settings.

\section{Reciprocity and Fair Trade Learning}

In 2016, FK Norway ${ }^{6}$ commissioned an international expert Benjamin Lough to draft a report setting out the Norwegian model of 'international volunteer service' recasting volunteers as agents of change working in more equitable and balanced relationships with their partners in host countries. The report identifies reciprocity as the core value guiding the ethics of these exchanges. In line with the critiques of more traditional donor-recipient models of 'volunteering' it acknowledges the fundamental asymmetry responsible for the dependencies and harms associated with professional voluntarism. Citing Polonijo-King (2004) Lough refers to concerns that 'unidirectional aid relationships ultimately rob recipients of self-respect using altruism as a form of social oppression' (p.109). He goes on to propose that 'reciprocal learning is one expression of strategic reciprocity [ ... ] disrupting the helping narrative' (pl0). This resonates with our own experience of managing EEPs. The concept of 'student' is far more balanced than that of 'volunteer' and enables local hosts to conceptualise themselves as active participants in an exchange relationship rather than as the passive recipients of foreign 'expertise'. These forms of symbiosis are most evident in engagements involving not only academic partners (as traditional student exchanges) but also service or non-academic partners. Sharpe and Dear (2013) use the concept of 'International Service-Learning' or 'ISL' to describe

\footnotetext{
${ }^{6}$ FK Norway is a part of the Norwegian national developmental policy. It was established in 1963 to send people from Norway, and was reorganised in 2000 to do mutual exchange: http://www.fredskorpset.no/en/about-us /
} 
university programmes in the US that 'combine academic instruction and community service in an international context' (2013: 49). The ISL approach has more in common with our concept of Ethical Educational Placements than the commodified products offered to consumers of volunteer tourism. In addition to the kinds of 'personto-person' reciprocity evident in the relationships that mobile students have with their peers and health workers, Lough underlines the role of organisational reciprocity in supporting effective and balanced interventions.

A critical component of the success of the EEP model lies in the partnerships that underpin and operationalise it. According to Wearing and McGehee the organisations that engage in the operation of volunteer tourism are a key factor in maximising good practice (2013: 124). Knowledge for Change (K4C) as a social enterprise plays a critical brokerage function linking key stakeholders including the University of Salford, Mountains of the Moon University, Uganda and Kabarole Health District. Hartman et al. argue that the 'unique mission, research, and evaluation capacities of higher education' places universities centre stage in the university-community nexus facilitating opportunities for 'best practice' maximising the benefits and minimising the negative impacts for host communities and volunteers. Whilst we would prefer to see the EEP model as conveying ethical standards for educational placements (as opposed to volunteer tourism) we would concur with their view that universities have institutional characteristics which make them 'ideal catalysts' (p. 109) for change. These typically include a not-for profit foundation; public serving missions with a focus on education, academic expertise in research, a research-based understanding of international development and an inherent commitment to challenging inequality, dependency and injustice. Wearing and McGehee refer in their review of the literature on volunteer tourism, a shift towards a more 'scientific' critique of the phenomenon involving more structured, interdisciplinary, transnational and mixed-methods studies (2013: 122). ${ }^{7}$ All of the organisations involved must also commit to principals of good governance and the

\footnotetext{
${ }^{7}$ They couch this discussion as lying at the intersection of tourism and volunteering research; we would argue that there are other perhaps more insightful theoretical insights to be had here from studies of mobility and internationalisation in higher education and careers.
} 
promotion of transparency and accountability. ${ }^{8}$ This is the cornerstone of trust and trust lies at the heart of partnership relationships.

The University partners in the EEP pilot provide important support and credibility to educational placements. Salford University, by way of example, underwrites the risk assessment process drawing on significant expertise in placement management. As a not-for-profit organisation committed to education and training it provides a level of credibility for potential students seeking out placement opportunities that is not found amongst private sector companies. The EEP secretariat is firmly based in Salford's prestigious Knowledge and Place Research Group ensuring a firm grounding in research on internationalisation processes, global health and research/evaluation methodology. As such EEPs represent a prime example of evidence-based policy. The University also supports high level dissemination of the EEP model encouraging other placement providers to reflect on their programmes and consider whether they can improve on the learning environment and ensure that they comply with ethical principles. The Universities in Uganda provide a similar assurance of support for students when on placement and a focus on learning and knowledge exchange. Working with these partners opens unique opportunities for peer-peer co-working but also harnesses and facilitates the role that Community Universities (such as MMU) play in delivering training to health workers in their hinterland. The link with Kabarole District is also essential to ensure that proper systems are in place and senior managers are aware of the presence and activities of volunteers and students. Also that they are given the opportunity to discuss and negotiate those interventions creating new opportunities and minimising the potential for unintended consequences. Once these relationships are established and respected $\mathrm{K} 4 \mathrm{C}$ can then operate at a more detailed level in the negotiation of specific tailored placements linked into active on-going project interventions with key actors within the District including health facilities and collaborating partners. An effective and respected intermediary with the capacity to manage relationships and maintain a close understanding of context is critical to this process. The intermediary also plays an essential role in managing and mitigating risk and operationalising the risk assessment process which is necessarily fluid and reactive.

${ }^{8}$ Governance is identified as one of the cornerstone principles of Fair Trade: http://www.fairtrade.org.uk/en/what-is-fairtrade/the-impact-of-our-work/ our-theory-of-change 
On another level the intermediary organisation has a fundamental role to play in ensuring compliance with ethical principles. As with risk, ethical compliance is an on-going process involving constant negotiation and mediation. The issues are complex and confounded by the innovative dynamics of global inequalities and corruption. Every intervention generates externality effects (unintended consequences) many of which are difficult to predict.

\section{The Multiplier Effects of Student Consumption}

Chapter 4 identified a number of ways in which EEPs have made a sustainable impact on local health systems in Uganda through the 'Fair Trade Premium'. We did not include in that discussion the wider economic impacts associated with students as consumers in local economies. However, anyone who has been involved in touristic activities in Uganda will see how important students and volunteers are to local tourism; the majority of participants in touristic visits in Uganda are volunteers or students often undertaking tourism alongside other activities. Hartman et al. extend their concept of Fair Trade Learning to consumption behaviour suggesting that programmes should take care to use 'local eateries' and source local products including local guides. We would support that assertion and have taken strides to discourage donations of equipment from the UK preferring wherever possible to source medical equipment in-country. We have been fortunate to have the intelligence and connections of our sister bio-medical engineering project to support us in this work. An example of this can be seen in the endeavours of a group of returned students actively wishing to continue their involvement in Uganda and respond to an identified need (for cervical cancer treatment). The students had taken part in the YAWE cervical screening work (Case Study 4) but were concerned that many women who were tested positive then had to make a 5-6-hour journey to Kampala for (potential) treatment. They therefore decided on return to raise funds for a cryotherapy machine to co-develop a local service. $\mathrm{K} 4 \mathrm{C}$ became involved in this taking advice from the biomedical engineering project and seeking in the first instance to procure equipment from Uganda providers. Having researched the situation, we have decided to source an alternative machine not yet available in Uganda but less reliant upon expensive consumables. K4C have since agreed to support this service providing the engineering and clinical training with the support of our long-term volunteers to ensure the equipment functions effectively for a minimum of three years. 
Hartman et al. also advocate the use of host families in the host setting to accommodate students. This is something we have chosen as a project not to engage in for a number of reasons. The students on EEPs are first and foremost professionals and not tourists and, on that basis, we feel it is important that they do not live with local families. From a risk perspective, we have preferred to organise our own premises and ensure that students have access to the facilities they need to maintain contact with their home universities and families. Many of the EEP students are mature students with partners and children and many continue to engage in elements of coursework during their placements. We also ask them to prepare teaching materials and weekly reports and prefer to provide them with the facilities to do that. Students on placement in the UK would not live with local families and we do not feel this contributes to their professional identity and external perceptions of them as students on educational placements. We have also found that students faced with quite challenging placements need to connect together in the evenings to debrief and share experiences with their peers, placement managers and supervisors. Having said that we have engaged our sister project (OBAAT) ${ }^{9}$ to undertake all of the building and repairs work using local builders engaged in capacity-building construction projects.

Sharpe and Dear's evaluation of 'International Service-Learning' (2013) echoes our own experiences and the importance of understanding the messiness of these kinds of interventions and the constant contradictions and unintended consequences muddying relationships between project rhetoric and practical reality. We present the EEP model in this book not as a static and perfectly formed 'model' but as a work in progress representing at least a commitment to progressive practice if not its complete realisation. The journey continues as we constantly try new things and reflect upon them. What is of utmost importance is that we continue to build upon our evidence base to improve the quality of the concept and its execution and, as Hartman et al. advocate, 'move forward in a sector increasingly dominated by a noxious combination of slick marketing and under-informed consumers'.

The emphasis on community-engagement and multi-disciplinarity in Hartman's 'Fair Trade Learning' has been taken a step further in our current plans to develop a series of integrated multi-disciplinary group

${ }^{9}$ See note 53 . 
projects in line with Salford University's employability agenda. ${ }^{10}$ The plans for these placements follows similar lines to the existing EEP model but with greater emphasis on the identification of a specific need or project by local stakeholders and the recruitment of explicitly multidisciplinary student teams to support an intervention. By way of illustration, one of the projects we are currently recruiting to involves a planned relationship between the Ugandan and UK Blood Transfusion Services designed to reduce mortality and morbidities associated with poor access to blood. The supply of blood in Uganda is constrained by a whole range of factors including donor awareness and behaviour, the lack of capacity in equipment management and repair, lack of capacity in laboratory management and skills and problems with power (to supply cold chain networks) and transportation. There is also no capacity in Uganda at the present time for cell salvage to enable patients to receive their own blood during operations taking the pressure off donor blood supplies, reducing costs and improving safety. The problems call for multi-disciplinary complex interventions involving many different stakeholders and all kinds of knowledge. We hope that the kinds of knowledge clusters generated within the EEP programme will enable us to mount an effective if incremental approach to such challenges.

\section{Early Career Mobility and Global Citizenship}

All studies of student mobility concur on one thing; that early stage mobility is an important precursor of subsequent mobility. We have expressed some concerns (above) that the kinds of mobility associated with 'electives' has been largely restricted, until recent years, to the mobilities of the privileged and noted that this reflects not solely income differentials but also differences in life experiences and exposure to mobility in their lives. One of the key findings of the EEP study has been the confidence and thirst the opportunity has given to young people with little previous experience or perhaps even interest in global health to consider future visits. It is interesting to see how cadres of students who would have had little opportunity to spend time in a low resource setting subsequently talk about their futures. We have referred to the specific challenges of

${ }^{10}$ We have received funding to develop and pilot these through Salford University's Higher Education Innovation Fund (HEIF). 
placing students in cadres that do not even exist in Uganda. This hasn't stopped one of the podiatry students planning to work abroad in future. Interestingly she also talks very positively about the attractiveness of multidisciplinary working:

I'm so glad I did it, and it's helped me realise what I want to do future and I know that I want to work abroad. It's made it a lot clearer. It's helped me realise what type of thing I want to go into. I want to work with high-risk things and with multidisciplinary areas.

Another student, this time in prosthetics also expresses a desire to plan a longer stay in a low resource setting in future:

Even though we weren't there for too long, we felt like we made a big difference in people's lives. It has definitely given me the motivation to do something like this again. I have always wanted to do some care relief work in developing countries, and I definitely will now, even if it's just for a couple of years.

The final section summarises the key ingredients of the Ethical Educational Placement Model.

\section{EEP MODEL}

\section{Infrastructure Investment Through Partnership-Building}

\section{Sending Organisations}

Phase 1 requires the establishment of 'Fit-For-Purpose' Sending Organisations.

Ideally these would involve a combination of a Registered Charity $(\mathrm{NGO})^{11}$ working in partnership with a Higher Education Institution (with not-for-profit and explicit educational objectives).

Identification of key managerial roles in sending and receiving locations (to include an overall Project Manager and Placement Leads in both locations). Individuals in these roles need a firm grounding in the

${ }^{11}$ We note in Ackers and Ackers Johnson (2016) the importance of these organisations operating within the spirit and letter of UK equality law. 
context and capacity-building objectives. It is essential not to underestimate the level of commitment and investment required to ensure that individuals with the right level of knowledge and skills are employed in these positions. Financial Planning and Transparency is essential.

\section{Host Organisations}

This includes the identification and formation of firm trust and governance relationships with partners ${ }^{12}$ in the hosting setting established through continuous collaboration. Ideally these would involve local HEIs partnership with relevant local stakeholders. From an ethical perspective we would advocate working only within the frame of public services and those NGOs committed to supporting pubic services.

Where appropriate objective setting processes and objectives should be formalised through a Memorandum of Understanding or similar agreement. This needs to be a 'living' document responsive to the outcomes of evaluation (below) with periodic review built in.

\section{Professional Volunteers}

Deployment of Professional Volunteers to support Partnership capacitybuilding objectives. The EEP Volunteer Agreement combines capacitybuilding roles in PUBLIC facilities with co-teaching in HEIs and placement supervision (of UK and Local students in knowledge clusters). ${ }^{13}$

\section{Placement Operationalisation}

Once infrastructure and active partnership working with established goals are in place planning can commence for placements.

Where possible ethical educational placements should be Integrated within Undergraduate Curricula rather than sitting outside of them in the form of 'electives'. This should expose them to full interrogation from

${ }^{12}$ This could be a Health Partnership or a partnership with local schools, for example.

${ }^{13}$ Further details of Professional Volunteer deployment and Volunteer Agreements are provided in Ackers et al. (2016) and Ackers and Ackers-Johnson (2016). 
equality and ethical perspectives and ensure that curriculum-relevant learning is actively validated.

This requires attention to undergraduate curricula to ensure a firm grounding in Ethics and Global Health /International Development in Undergraduate Curricula (including cultural competence) for ALL students. ${ }^{14}$

Comprehensive and Fair Recruitment processes complying with best practice in equal opportunities including maximum exposure to opportunities available, open advertisement of opportunities and rigorous selection criteria (where bursaries are involved). Clear procedures re disclosure of health and other conditions to ensure that all students have the necessary resilience to cope with a placement and team-working.

Comprehensive and tailored approach to Pre-departure Training and Induction; ideally combining provision of regularly up-dated Induction and Orientation materials with opportunities for one-on-one email and face-to-face communication. To include expectations management. Where possible, engagement of host partners in this process.

The Induction Pack should contain links to full Risk Assessment and a bespoke and comprehensive Insurance Policy. Wherever possible students (and Professional Volunteers) should be covered by a Common Policy to ensure rapid and effective response to crises and ensure there are no gaps in cover.

Centrally planned and clearly communicated logistical arrangements need to be in place to ensure the management of student journeys from initial expression of interest to final post-return reporting/reflection. Particular attention to in-country travel, provision of risk-assessed accommodation with amenities necessary for completion of an effective and professional educational placement (this will vary according the local context). Provision of services of a Local Placement Manager actively engaged within the overall Partnership activity (as above). The local placement manager will work alongside Professional Volunteers and project managers to ensure effective debriefing and pastoral care.

${ }^{14}$ This is an area that we are currently working on and was not fully established prior to deployment of EEP students. The research has suggested this is necessary to prepare students and promote optimal learning and guard against the concerns expressed about 'essentialized concepts of 'other' (Simpson cited in Chapter 5). 
Establishment of a Placement Agreement providing generic clarity on student roles on placement, codes of conduct (including disciplinary procedures), co-presence and supervision/mentoring with an additional tailored component specific to each individual student. This should be seen as an iterative agreement established prior to departure but subject to negotiated revision during the placement in response to changing needs and contexts.

Financial planning and governance requirements (above) extend to the relationships with local hosts and the management of the Fair Trade Premium. Serious consideration should be given to any cash payments and avoided wherever possible. Local stakeholders should be actively involved at the appropriate level where possible involving local health workers in decisions about local investments to support joint decisionmaking and effective outcomes.

\section{Evaluation and Iterative Review}

Integrated Evaluation of the wider capacity-building initiative and within that, the Placement Review. This is as an on-going requirement to ensure that all of the above are adhered to and optimal outcomes achieved (including attention to 'no harm' principles). Placement review and reporting should include written weekly reports and focus group meetings supported, where necessary, by opportunities for personal discussions with the Local Placement Manager.

Open Access This chapter is licensed under the terms of the Creative Commons Attribution 4.0 International License (http://creativecommons.org/licenses/ by $/ 4.0 /$ ), which permits use, sharing, adaptation, distribution and reproduction in any medium or format, as long as you give appropriate credit to the original author(s) and the source, provide a link to the Creative Commons license and indicate if changes were made.

The images or other third party material in this chapter are included in the book's Creative Commons license, unless indicated otherwise in a credit line to the material. If material is not included in the book's Creative Commons license and your intended use is not permitted by statutory regulation or exceeds the permitted use, you will need to obtain permission directly from the copyright holder.

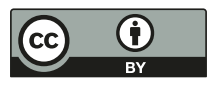

